\section{Alterations of the tear film and ocular surface health in chronic smokers}

Y Matsumoto', M Dogru' ${ }^{2,3}$, E Goto $^{4}$, Y Sasaki ${ }^{3}$, H Inoue ${ }^{5}$, I Saito ${ }^{5}$, J Shimazaki ${ }^{2}$ and K Tsubota ${ }^{3}$

\begin{abstract}
Objective To investigate the effects of chronic smoking on ocular surface and tear functions.

Methods Fifteen right eyes of 15 healthy chronic smokers ( 9 men, 6 women; age range: 36-47 years) who smoked 20 cigarettes per day for 20 years and 20 eyes of 20 control nonsmokers (12 men, 8 women; age range: $38-43$ years) were included in this prospective study. All subjects underwent measurements of breath and haemoglobin $\mathrm{CO}$ concentration, tear lipid layer interferometry, evaporimetry, tear film break-up time (TBUT), Schirmer's I test, corneal fluorescein staining, conjunctival impression, and brush cytology.

Results The mean $\mathrm{Hb} \mathrm{CO}$ level was significantly higher in smokers compared to non-smokers. TBUT was also significantly shorter in smokers. Tear lipid layer showed significant slowing in spread over the tear film with a concomitant significant increase in tear evaporation rate. Conjunctival impression cytology revealed significant loss of goblet cells and squamous metaplasia in smokers. Brush cytology showed significant conjunctival neutrophil infiltration in smoker subjects. Conclusion Chronic smoking induced distinctive quantitative and qualitative disturbances on the ocular surface health. Eye (2008) 22, 961-968; doi:10.1038/eye.2008.78; published online 18 April 2008
\end{abstract}

Keywords: dry eye; smoking; cytology; tear lipid layer

\section{Introduction}

Cigarette smoke is an essential source of intake of heavy metals and toxic mineral elements, all known to be poisonous in high concentrations. ${ }^{1}$ These toxic compounds have multiple adverse physiologic effects with profound pathological disturbances in different organs, including the eye. Fume particles and noxious gases such as nicotine and carbon monoxide may influence the circulatory system by inducing profound vasospasm, platelet aggregation, or leading to oxidative damage to lipids, proteins, and cellular DNA. $^{2-8}$

Epidemiological data link cigarette smoking as a risk factor for many ophthalmological disorders including strabismus in offspring of pregnant smokers, anterior ischaemic optic neuropathy, age related macular degeneration, cataract, thyroid ophthalmopathy, primary open angle glaucoma, diabetic retinopathy, uveal melanoma, conjunctival intraepithelial neoplasia, ocular sarcoidosis, and development of dry eyes. ${ }^{9-26}$ The Beaver Dam Study related current active smoking and past history of smoking to a higher prevalence of dry eye disease. ${ }^{27}$ The Blue Mountain Eye Study also recognized smoking as an important risk factor for dry eyes. ${ }^{28}$ Demographic surveys have shown that $25-40 \%$ of employees experience cigarette smoke in their work environment and that $25 \%$ of them have dry eye related symptoms. ${ }^{5}$ Despite the availability of important epidemiological data on hazardous effects of cigarette smoke, there are surprisingly only a few studies related to the alterations of the ocular surface and tear functions in cigarette smokers.

In this study, we investigated the effects of long term exposure to cigarette smoke on the tear film and ocular surface health of in chronic healthy smokers and compared the results with those of non-smoker subjects.

\section{Materials and methods}

Fifteen eyes of 15 chronic healthy smokers ( 9 men, 6 women; age range: $36-47$ years) and 20
'Department of Ophthalmology, Keio University School of Medicine, Tokyo, Japan

2J and J Department of Ocular Surface and Visual Optics, Keio University School of Medicine, Tokyo, Japan

${ }^{3}$ Department of Ophthalmology, Tokyo Dental College, Chiba, Japan

${ }^{4}$ Department of Ophthalmology, Tsurumi University School of Dental Medicine, Yokohama, Japan

${ }^{5}$ Department of Pathology, Tsurumi University School of Dental Medicine,

Yokohama, Japan

Correspondence: M Dogru, $J$ and J Ocular Surface and Visual Optics Department, Keio University School of Medicine,

Shinanomachi 35 Shinjuku-ku, Tokyo, Japan

Tel: + 8135363 3820;

Fax: + 81333598302

E-mail: muratodooru@

yahoo.com

Received: 23 September 2007

Accepted in revised form: 19 February 2008 Published online: 18 April 2008 
eyes of 20 control non-smokers (12 men, 8 women; age range: $38-43$ years) were included in this prospective study. Subjects who smoked 20 cigarettes per day for 20 years were included as chronic smokers according to the protocol of the study. Passive smoking status was determined by asking the control subjects about the presence of smoking history among household members or at work. Control subjects with a history of passive cigarette-smoke exposure or who spent substantial time in a smoky atmosphere at home or at work within the last 6 months were excluded from the current study. Smoking status was evaluated by calculating the pack years of cigarette smoking (the average number of cigarettes per day times the number of years of smoking) which served as a measure of cumulative exposure. ${ }^{29}$ At the time of enrolment and acquisition of informed consents when the appointments for $\mathrm{CO}$ measurements and tear function tests were made, smokers were requested not to smoke for at least $6 \mathrm{~h}$ before their examinations on the morning of the testings for breath and haemoglobin $\mathrm{CO}$ concentrations. Examination procedures were board reviewed and informed consent was obtained from all subjects.

\section{Examinations and study exclusion criteria}

Subjects with contact lenses, ocular diseases including meibomian gland dysfunction, blepharitis, infectious keratoconjunctivitis, systemic diseases with known associations to ocular surface diseases were excluded. Subjects who were diagnosed as having dry eyes according to the diagnostic criteria of the Dry eye Research Group in Japan, were also excluded from the study. $^{30}$

\section{Ocular symptoms}

All subjects were asked about the presence of ocular symptoms and to state their worst symptom. Smokers were asked if their worst symptom intensified while they were smoking and were requested to choose from one of the following options in relation to the frequency of symptom intensification while smoking: 'always', 'often', 'occasionally', 'rarely', and 'never'.

\section{Breath CO measurement}

Exhaled CO measurements were performed as reported previously with the Micro-Smokerlyzer (Bedfont Scientific Ltd, UK) sensitive to CO from 0 to 250 p.p.m. by volume. Blood carboxyhemoglobin concentrations were also displayed by the device and recorded in each case. ${ }^{31}$

\section{Tear function parameters}

All tear function and ocular surface examinations were carried out under the same settings with the room temperature at $22^{\circ} \mathrm{C}$ and humidity between 50 and $60 \%$.

\section{Tear evaporation rate}

The tear film evaporation rate was measured as described previously by using a tear evaporimeter (KAO Corporation, Tokyo, Japan) following the manufacturer's instructions. ${ }^{32}$

\section{DR-1 lipid layer interferometry}

Lipid layer interference images were recorded by the DR-1 interferometer device (DR-1 Kowa Co., Nagoya, Japan) soon after a complete blink. ${ }^{33}$ In this study, tear film lipid spread time was defined as the time from the end of a complete blink until a stable lipid layer fringe pattern was attained in the DR-1 interferometer. Lipid spread time was measured three times and the mean value was calculated.

\section{Tear hexanoyl-lysine ELISA analysis}

Being a marker for initial stage of lipid peroxidation, we investigated the changes in the tear hexanoyl-lysine (HEL) concentration in response to a possible reactive oxidative species burden. Tear samples were taken from each eye, using a $2 \mu \mathrm{l}$ capillary tube to analyse tear HEL concentration. HEL ELISA kits (Nikken Seil Co. Ltd, Shizuoka, Japan) were used to determine the tear HEL concentrations, as reported previously. ${ }^{34}$

Tear film break-up time

Two microlitres of $1 \%$ fluorescein and Rose Bengal containing preservative free solution were applied in the conjunctival sac with a micropipette. ${ }^{35}$ The standard tear film break-up time (TBUT) measurement was performed by instructing the subjects to blink several times for a few seconds to ensure adequate mixing of the dye. The interval between the last complete blink and the appearance of the first corneal black spot in the stained tear film was measured three times and the mean value of the measurements was calculated. A TBUT value of less than $10 \mathrm{~s}$ was considered abnormal.

\section{Ocular vital staining scores}

Two microlitres of $1 \%$ fluorescein and Rose Bengal containing preservative free solution were applied in the conjunctival sac with a micropipette. Fluorescein staining scores of the corneas ranged between 0 and 9 points. Any score above three points was regarded as abnormal. ${ }^{35}$

\section{Schirmer's I test}

For further evaluation of tears, the standard Schirmer's test without topical anaesthesia was performed as 
recommended by the 2007 Dry Eye Workshop report. ${ }^{36}$ The sterilized strips of filter paper (Showa Yakuhin Kako Co. Ltd, Tokyo, Japan) were placed in the lateral cantus away from the cornea and left in place for $5 \mathrm{~min}$. Readings were repeated in millimetres of wetting for 5 min. $^{36}$

\section{Impression cytology parameters}

The impression cytology (IC) specimens were obtained after administration of topical anaesthesia with $0.4 \%$ oxybuprocaine. Two separate strips of cellulose acetate filter paper (Millipore HAWP 304, Bedford, MA, USA), that were soaked in distilled water for a few hours and dried at room temperature, were applied on adjacent the medial bulbar conjunctiva, pressed gently by a glass rod, and then removed.

The specimens were then fixed with formaldehyde, stained with Periodic acid-Schiff (PAS), dehydrated in ascending grades of ethanol and then with xylol, and finally mounted with coverslips. Goblet cells were counted in three nonoverlapping areas in each specimen, chosen at random with the help of a calibrated grid. Squamous metaplasia was assessed in the same areas at a magnification of $\times 400$. The goblet cell densities were reported as cells per square millimetre with standard deviations. The specimens were also assigned a grade of conjunctival epithelial squamous metaplasia according to Nelson's grading scheme. ${ }^{37}$

\section{Brush cytology}

The brush cytology specimens were obtained after administration of topical anaesthesia with $0.4 \%$ oxybuprocaine. An area of medial bulbar conjunctiva, which did not undergo IC, was used for sampling. Conjunctiva was scraped seven times with the Cytobrush-S (Medscand AB, Sweden), the examiner holding the brush $2 \mathrm{~cm}$ away from the brush end, applying a gentle pressure to the conjunctiva. After sampling, the brushes were immediately placed in $1 \mathrm{ml}$ of Hank's buffered solution, and the containers were shaken in order to detach the cells from the brush. The suspended cells were collected using the Millipore filter technique employing filters with $8 \mu \mathrm{m}$ pore size.

The samples were allocated for the assessment of conjunctival inflammatory cell numbers by Diff-Quik staining. The inflammatory cells were counted from 10 nonoverlapping fields and the means were calculated for purposes of this study.

\section{Statistical analysis}

Mann-Whitney test was used for statistical comparisons. A $P$-value less than 0.001 was considered statistically significant. Statistical analysis was performed by using Instat (GraphPad software, San Diego, USA).

\section{Results}

The cumulative exposure to cigarette smoke was 400 pack years in chronic smokers. None of the control subjects had actively smoked cigarettes and had a history of passive smoke exposure at home or at work in the current study.

\section{Exhaled CO concentrations}

Exhaled CO and blood haemoglobin levels were detectable in all subjects. The mean exhaled $\mathrm{CO}$ concentration in smokers and control subjects were $16.6 \pm 9.7$ p.p.m. and $1.3 \pm 1.3$ p.p.m., respectively (smokers, median: 10 p.p.m., upper 95\% CI: 22.07 p.p.m., lower 95\% CI: 11.2 p.p.m.; non-smokers, median: 2 p.p.m., upper $95 \%$ CI: 2.07 p.p.m., lower $95 \%$ CI: 0.58 p.p.m.). The differences were statistically significant $(P<0.0001)$. The mean $\mathrm{CO}$ concentration in serum haemoglobin in smokers and control subjects were $4.8 \pm 0.4 \%$ and $0.5 \pm 0.5 \%$, respectively (smokers, median: $4.8 \%$, upper $95 \%$ CI: $5.04 \%$, lower $95 \%$ CI: $4.63 \%$; nonsmokers, median: $0.9 \%$, upper $95 \%$ CI: $0.82 \%$, lower $95 \%$ CI: $0.24 \%)$. The differences were statistically significant $(P<0.0001)$.

\section{Ocular symptoms}

Out of 15 smokers, 12 (80\%) reported ocular symptomatology. The worst symptoms included burning sensation, irritation, foreign body sensation, tiredness, and dryness. Eight smokers $(53.3 \%)$ reported that their worst symptom always intensified after smoking. Three smokers $(20 \%)$ stated often and one smoker $(6.7 \%)$ noted occasional intensification of their worst symptom when they smoked. Three smokers (20\%) never experienced intensification of their worst symptom after smoking.

\section{Tear function parameters}

Tear evaporation rate

The mean tear evaporation rates in smokers and control subjects were $7.7 \pm 0.2$ and $2.5 \pm 0.9 \times 10^{-7} \mathrm{~g} / \mathrm{cm}^{2} / \mathrm{s}$ respectively (smokers, median: 7.5 , upper $95 \%$ CI: 7.87 , lower 95\% CI: 7.59; non-smokers, median: 2.4, upper $95 \%$ CI: 3.03 , lower $95 \%$ CI: 1.96). The differences were statistically significant $(P<0.0001)$.

\section{DR-1 lipid layer interferometry}

The mean lipid spread times in chronic smoker subjects and non-smoker controls were $2.5 \pm 0.5$. and $1.2 \pm 0.2 \mathrm{~s}$, 
respectively (smokers, median: 2.34 , upper $95 \%$ CI: 2.85 , lower 95\% CI: 2.23; non-smokers, median: 1.17, upper $95 \%$ CI: 1.33, lower $95 \%$ CI: 1.05). The differences were statistically significant $(P<0.0001)$.

Two types of lipid layer spread abnormality were observed. We observed complete lipid spread after a full blink but with instant appearance of multiple break-up points suggesting tear instability in 22 eyes (Figure 1a). In the other eight eyes, we noted incomplete and irregular lipid spread (Figure 1b). All control subjects had complete spread of the tear film with a complete blink as shown in Figure 1c.

\section{Tear hexanoyl-lysine ELISA analysis}

The mean tear HEL levels in smokers and control subjects were $380 \pm 18$ and $336 \pm 20 \mathrm{nmol} / \mathrm{l}$, respectively (smokers, median: 388 , upper 95\% CI: 390, lower 95\% CI: 370; non-smokers, median: 322 , upper $95 \%$ CI: 347 , lower 95\% CI: 324). The mean tear HEL value was significantly elevated in smokers compared to the control subjects $(P<0.0001)$.

\section{Tear film break-up time}

The mean TBUT was significantly lower in smokers $(3.2 \pm 0.7 \mathrm{~s})$ compared to non-smoker controls (14.2 $\pm 2.4 \mathrm{~s}$; $P<0.0001$; smokers, median: 3 , upper $95 \%$ CI: 3.57 , lower 95\% CI: 2.82 , non-smokers, median: 14 , upper $95 \%$ CI: 15.6, lower 95\% CI: 12.9 ).

\section{Ocular vital staining scores}

Only one non-smoker control had a positive corneal fluorescein staining (1 point). The mean fluorescein staining score of smokers was $2.86 \pm 0.35$ points which was significantly higher than the non-smoker controls whose score was $0.07 \pm 0.26$ points $(P<0.0001$, smokers, median: 3, upper $95 \%$ CI: 3.06, lower 95\% CI: 2.67; non-smokers, median: 0, upper $95 \%$ CI: 0.22 , lower $95 \%$ CI: 0.08).

\section{Schirmer's test}

There was no significant difference in Schirmer's test values between smokers $(13.3 \pm 2.1 \mathrm{~mm})$ and non-smoker controls (17.1 $\pm 2.6 \mathrm{~mm} ; P>0.05)$.

\section{Impression cytology parameters}

The mean squamous metaplasia grade was significantly higher in smokers than the controls $(P<0.0001)$. The mean goblet cell density was significantly reduced in smokers compared to non-smoker controls as shown in Figure $2 \mathrm{a}(P<0.0001)$. IC specimens from healthy control subjects revealed numerous goblet cells, abundant mucin pickup, and sheets of normal conjunctival epithelial cells (Figure 2b). Specimens from smokers revealed either a few or no goblet cells and epithelial cells with advanced squamous metaplasia (Figure 2c-d).

\section{Brush cytology for inflammatory cell counts}

$\mathrm{BC}$ revealed decreased intercellular cohesiveness and a significantly higher number of neutrophils in smokers compared to non-smoker controls (Figure 3a). BC specimens from control subjects did not reveal any inflammatory cells (Figure $3 \mathrm{~b}$ ). BC specimens from smokers showed numerous neutrophils, some interspersed among sheets of conjunctival epithelial cells (Figure 4).

\section{Discussion}

Cigarette smoking has been reported to be one of the factors in the array of clinical conditions, resulting in a dysfunctional tear film. ${ }^{38,39}$ It is well known that the tar and gas phases of tobacco contain many oxidizing substances exposing inhalers to an enormous free radical load..$^{40}$ Although the ocular surface is the most environmentally exposed mucosal surface of the body, including tobacco smoke exposure, only four studies in the literature reported data concerning the effects of
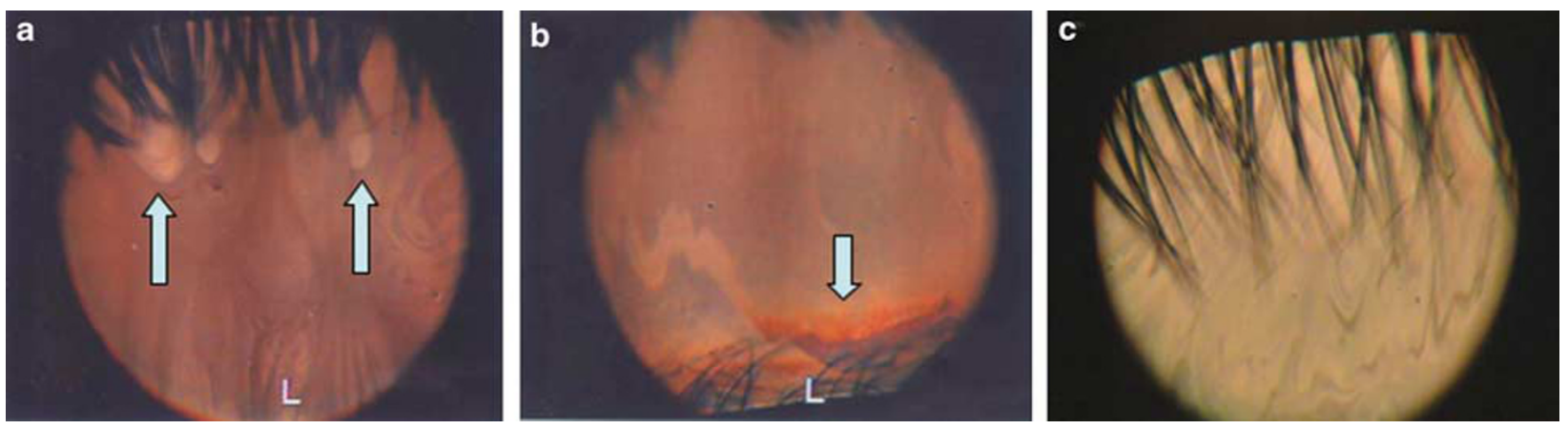

Figure 1 DR-1 tear film lipid layer observations in chronic smokers. (a) Type I abnormality: note the complete spread of the tear film lipid with multiple lipid layer break up points (blue arrows) soon after the full blink. (b) Type II abnormality: note the incomplete and irregular spread of the tear film lipid layer soon after the full blink (blue arrow). (c) Normal tear film: note the complete spread of the tear film lipid layer with a full blink in a normal subject. 


\begin{tabular}{|c|c|c|}
\hline $\begin{array}{c}\text { Impression } \\
\text { Cytology } \\
\text { parameter }\end{array}$ & Smoker & Nonsmoker \\
\hline $\begin{array}{c}\text { Squamous } \\
\text { Metaplasia } \\
\text { Grade }\end{array}$ & $2.5 \pm 0.5^{*}$ & $0.3 \pm 0.4$ \\
\hline $\begin{array}{c}\text { Globlet cell } \\
\text { density } \\
\left.\text { (cells/mm } / \mathrm{mm}^{2}\right)\end{array}$ & $30 \pm 68 *$ & $1318 \pm 295$ \\
\hline
\end{tabular}

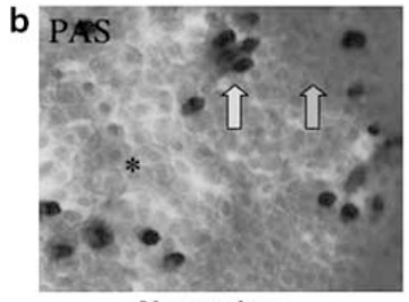

Nonsmoker

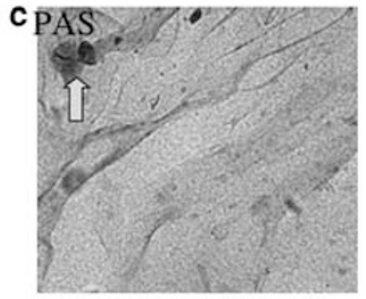

Smoker specimen-1

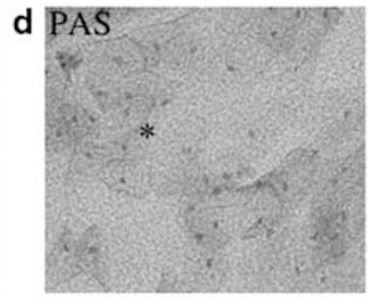

Smoker specimen-2

Figure 2 Comparison of impression cytology findings between chronic heavy smokers and non-smoker controls. (a) Note the significantly higher squamous metaplasia grade and the significant reduction in goblet cell density in chronic heavy smokers. (b) Note the presence of numerous goblet cells (blue arrow), sheets of healthy conjunctival epithelial cells (asterisk mark) and abundant mucin pickup by the filter paper (pink arrow). (c) Note the dramatic reduction of goblet cell numbers (blue arrow). (d) Note the advanced squamous metaplasia (asterisk mark) and absence of goblet cells in another representative specimen.

\begin{tabular}{|c|c|c|}
\hline $\begin{array}{c}\text { Conjunctival Brush } \\
\text { Cytology parameter }\end{array}$ & Smoker & Nonsmoker \\
\hline $\begin{array}{c}\text { Intercellular } \\
\text { cohesiveness }\end{array}$ & $\Downarrow$ & Normal \\
\hline $\begin{array}{c}\text { Neutrophil density } \\
\text { (cells/mm²) }\end{array}$ & $327 \pm 145 *$ & 0 \\
\hline
\end{tabular}

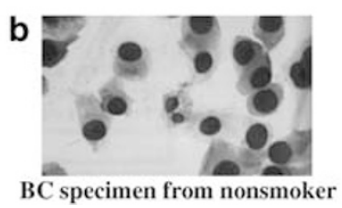

Figure 3 Comparison of brush cytology findings between chronic heavy smokers and non-smoker controls. (a) Note the lower neutrophil density in the heavy smokers. (b) Note the healthy conjunctival epithelial cells and absence of any neutrophils in the specimen from a non-smoker control subject.

cigarette smoke on the ocular surface and tear film characteristics. ${ }^{38,39,41,42}$ All four studies focused on the effects of active chronic smoking and concluded that smoking was associated with tear instability and deteriorating effects on the ocular surface health. Chronic smokers were also reported to have low corneal and conjunctival sensitivity, ${ }^{39}$ increased conjunctival squamous metaplasia, ${ }^{39}$ and alteration of tear proteins. ${ }^{7,41,42}$ In our previous study, we found tear film instability and abnormal lipid layer interferometry patterns in chronic smokers attributing these changes to a possible tear film lipid layer damage. ${ }^{39}$ In accordance with studies on tear film stability changes in chronic smokers, we reconfirmed significant perturbation of the tear film stability in our current work. We report a significant increase in tear evaporation rate and slowing of the tear film lipid spread time in chronic smokers compared to non-smoker controls for the first time in the literature. It is believed that the tear film lipid layer minimizes the evaporation of the aqueous component of the tear film in physiologic states and in adverse environments. ${ }^{43}$ The lipids, aqueous portion, and mucin components of the tear film are believed to interact with each other to achieve an even spread of the lipid layer in the tear film, rendering the cornea wettable and allowing tear stability within the normal limits. ${ }^{43}$ As none of the smoker subjects had an ocular/eyelid disease including blepharitis, infectious keratoconjunctivitis, and meibomian gland dysfunction in this study, the prolongation of lipid spread time consistently in all of our chronic smoker subjects may be explained by possible mucin changes in the ocular surface as evidenced by a reduction of goblet cell density and possible changes in the nature of tear lipids, as evidenced by increased tear HEL levels. Lipids are known to be potential targets for oxidative attack of free radicals. HEL is a useful biomarker for initial stage of lipid peroxidation, which can be detected in human atherosclerotic lesions, urine, serum, and tears. ${ }^{44}$ It should be noted though that the increase in tear HEL levels might not necessarily be a toxic change resulting from lipid peroxidation, but may be a physiological response to an increased reactive oxygen species burden. 


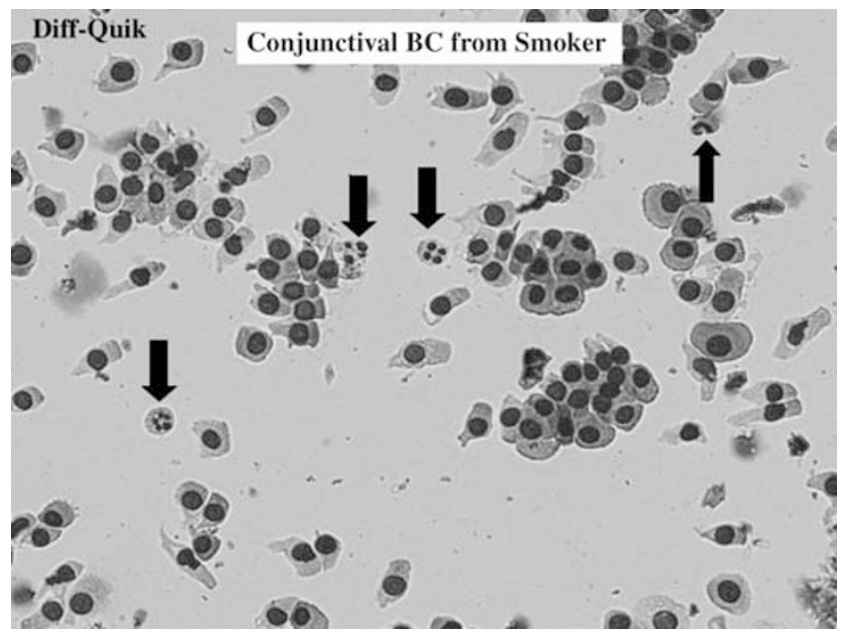

Figure 4 Representative conjunctival brush cytology specimen from a chronic heavy smoker subject. Note the presence of numerous neutrophils (blue arrows), which was a consistent finding from specimens of smoker subjects.

Increased tear hexanoyl-lysine in chronic smokers might have induced functional changes in the tear lipids and might explain the lipid spread alterations observed in the current study. Another explanation may be the decrease in conjunctival goblet cells in smokers which solely secrete MUC5AC into the tears, the major mucin thought to be responsible for the attainment of tear stability. ${ }^{45}$ A concomitant reduction in MUC5AC quantity in tears might have altered the interaction of mucins with tear lipids which should be investigated in future trials. A previous study did not reveal significant differences in goblet cell density between smokers and non-smoker controls, a finding which was different from the current study. ${ }^{38}$ The smoker subjects of this study were all symptomatic long-term smokers with a smoking history of greater than 20 years where the subjects of the previous report included chronic smokers with a variable duration of smoke exposure which may explain these differences.

BC examination also provided interesting findings. All BC specimens from the smokers in the current study consistently revealed neutrophil infiltrates, the densities of which were significantly higher compared to the nonsmoker controls. Although not investigated in the current study, an increase in ocular surface and tear inflammation ${ }^{46}$ has been shown to coexist with increased levels and activity of proteolytic enzymes, including plasmin and matrix metalloproteases, in dry eye syndromes resulting in ocular surface epithelial damage ${ }^{4-50}$ which might explain the higher fluorescein scores observed in the smokers.

In summary, our study confirmed the deleterious effect of chronic cumulative tobacco smoke exposure on the tear film and ocular surface health status. It would be interesting to investigate the effect of passive exposure to cigarette smoke on the ocular surface, tear film and visual status, an issue still uninvestigated in ophthalmic literature. It is our sincere wish that the adverse findings following chronic long-term cigarette-smoke exposure observed in this study alert all professionals for adoption of prevention policies especially by public and health officials.

\section{References}

1 Chiba M, Masironi R. Toxic and trace elements in tobacco and tobacco smoke. Bull World Health Organ 1992; 70: 270-276.

2 Hara K. Effects of cigarette smoking on ocular circulation chronic effect on choroidal circulation. Nippon Ganka Gakkai Zasshi 1991; 95: 939-943, [In Japanese].

3 Williamson TH, Lowe GDO, Baxter GM. Influence of age, systemic blood pressure, smoking, and blood velocity on orbital blood velocities. Br J Ophthalmol 1995; 19: 17-22.

4 Durak I, Yalcin S, Cimen MYB, Buyukkocak S, Kacmaz M, Ozturk HS. Effects of smoking on plasma and erythrocyte anti-oxidant defense systems. J Toxicol Environ Health 1999; 56: 373-378.

5 Weber A. Annoyance and irritation by passive smoking. Prev Med 1984; 13: 618-625.

6 van der Vaart H, Postma DS, Timens W, Ten Hacken NH. Acute effects of cigarette smoke on inflammation and oxidative stress a review. Thorax 2004; 59: 713-721.

7 Grus FH, Sabuncuo P, Augustin A, Pfeiffer N. Effect of smoking on tear proteins. Graefes Arch Clin Exp Ophthalmol 2002; 240: 889-892.

8 Kiyosawa H, Suko M, Okudaira H, Murata K, Miyamoto T, Chung $\mathrm{MH}$ et al. Cigarette smoking induces formation of 8-hydroxydeoxyguanosine, one of the oxidative DNA damages in human peripheral leukocytes. Free Radic Res Commun 1990; 11: 23-27.

9 Hakim RB, Tielsch JM. Maternal cigarette smoking during pregnancy. A risk factor for childhood strabismus. Arch Ophthalmol 1992; 110: 1459-1462. 
10 Chung SM, Gay CA, McCrary JA. Nonarteritic ischemic optic neuropathy. The impact of tobacco use. Ophthalmology 1994; 101: 781-783.

11 The Eye Disease Case-Control Study Group. Risk factors for neovascular age-related macular degeneration. Arch Ophthalmol 1992; 110: 1701-1708.

12 Christen WG, Glynn RJ, Manson JE, Ajani UA, Buring JE. A prospective study of cigarette smoking and risk of agerelated macular degeneration in men. JAMA 1996; 276: 1147-1151.

13 Seddon JM, Willett WC, Speizer FE, Hankinson SE. A prospective study of cigarette smoking and age-related macular degeneration in women. JAMA 1996; 276: 11411146.

14 Christen WG, Manson JE, Seddon JM, Glynn RJ, Buring JE, Rosner $\mathrm{B}$ et al. A prospective study of cigarette smoking and risk of cataract in men. JAMA 1992; 268: 989-993.

15 Hankinson SE, Willett WC, Colditz GA, Seddon JM, Rosner B, Speizer FE et al. A prospective study of cigarette smoking and risk of cataract surgery in women. JAMA 1992, 268: 994-998.

16 Prummel MF, Wiersinga WM. Smoking and risk of Graves' disease. JAMA 1993; 269: 479-482.

17 Morgan RW, Drance SM. Chronic open angle glaucoma and ocular hypertension: an epidemiologic study. $\mathrm{Br} \mathrm{J}$ Ophthalmol 1975; 59: 211-215.

18 Shepard RJ, Ponsford E, Basu PK, LaBarre R. Effects of cigarette smoking on intraocular pressure and vision. Br J Ophthalmol 1978; 62: 682-687.

19 Wilson MR, Hertzmark E, Walker AM, Childs-Shaw K, Epstein DL. A case-control study of risk factors in open angle glaucoma. Arch Ophthalmol 1987; 105: 1066-1071.

20 Marshall G, Garg SK, Jackson WE, Holmes DL, Chase HP. Factors influencing the onset and progression of diabetic retinopathy in subjects with insulin-dependent diabetes mellitus. Ophthalmology 1993; 100: 1133-1139.

21 Muhlhauser I, Sawicki P, Berger M. Cigarette-smoking as a risk factor for acroproteinuria and proliferative retinopathy in type 1 (insulin-dependent) diabetes. Diabetologia 1986; 29: 500-502.

22 Paetkau ME, Boyd TAS, Winship B, Grace M. Cigarette smoking and diabetic retinopathy. Diabetes 1977; 26: 46-49.

23 Sjolie AK. Ocular complications in insulin treated diabetes mellitus. An epidemiological study. Acta Ophthalmol Suppl 1985; 1: 172.

24 Egan KM, Gragoudas ES, Seddon JM, Walsh SM. Smoking and the risk of early metastases from uveal melanoma. Ophthalmology 1992; 99: 537-541.

25 Napora C, Cohen EJ, Genvert GI, Presson AC, Arentsen JJ, Eagle RC et al. Factors associated with conjunctival intraepithelial neoplasia: a case control study. Ophthalmic Surg 1990; 21: 27-30.

26 Merritt JC, Ballard DJ, Checkoway H, Mower P, Grimson R. Ocular sarcoidosis. A case-control study among black patients. Ann N Y Acad Sci 1986; 465: 619-624.

27 Moss SE, Klein R, Klein BE. Prevalence of and risk factors for dry eye syndrome. Arch Ophthalmol 2000; 118: 1264-1268.

28 Chia EM, Mitchell P, Rochtchina E, Lee AJ, Maroun R, Wang JJ. Prevalence and associations of dry eye syndrome in an older population: the Blue Mountains Eye Study. Clin Experiment Ophthalmol 2003; 31: 229-232.

29 Bernaards CM, Twisk JW, Snel J, Van Mechelen W, Kemper HC. Is calculating pack-years retrospectively a valid method to estimate life-time tobacco smoking? A comparison between prospectively calculated pack-years and retrospectively calculated pack-years. Addiction 2001; 96: 1653-1661.

30 The Japanese Community Study Group on Diagnostic Criteria for Dry Eye. Definition and criteria of dry eye. Ganka 1995; 37: 765-770, [In Japanese].

31 Ohara Y, Ohrui T, Morikawa T, He M, Yasuda H, Yamaya M et al. Exhaled carbon monoxide levels in school-age children with episodic asthma. Pediatr Pulmonol 2006; 41: 470-474.

32 Goto E, Endo K, Suzuki A, Fujikura Y, Matsumoto Y, Tsubota $\mathrm{K}$. Tear evaporation dynamics in normal subjects and subjects with obstructive meibomian gland dysfunction. Invest Ophthalmol Vis Sci 2003; 44: 533-539.

33 Goto E, Dogru M, Kojima T, Tsubota K. Computer-synthesis of an interference color chart of human tear lipid layer, by a colorimetric approach. Invest Ophthalmol Vis Sci 2003; 44: 4693-4697.

34 Tsuji K, Kawai Y, Kato Y, Osawa T. Formation of $\mathrm{N}$-(hexanoyl)ethanolamine, a novel phosphatidylethanolamine adduct, during the oxidation of erythrocyte membrane and low-density lipoprotein. Biofactors 2004; 21: 263-266.

35 Toda I, Tsubota K. Practical double vital staining for ocular surface evaluation [letter]. Cornea 1993; 12: 366-367.

36 Bron AJ, Abelson MB, Ousler G, Pearce E, Tomlinson A, Yokoi N. Methodologies to diagnose and monitor dry eye disease: report of the Diagnostic Methodology Subcommittee of the International Dry Eye Workshop. Ocul Surf 2007; 5: 108-152.

37 Nelson JD, Wright JC. Conjunctival goblet cell densities in ocular surface disease. Arch Ophthalmol 1984; 102: 1049-1052.

38 Satici A, Bitiren M, Ozardali I, Vural H, kilic A, Guzey M. The effects of chronic smoking on the ocular surface and tear characteristics: a clinical, histological and biochemical study. Acta Ophthalmol Scand 2003; 81: 583-587.

39 Altinors DD, Akca S, Akova YA, Bilezikci B, Goto E, Dogru $\mathrm{M}$ et al. Smoking associated with damage to the lipid layer of the ocular surface. Am J Ophthalmol 2006; 141: 1016-1021.

40 Pryor WA. Cigarette smoke and the involvement of free radical reactions in chemical carcinogenesis. $\mathrm{Br} J$ Cancer 1987; 55: S19-S23.

41 Yoon KC, Song BY, Seo MS. Effects of smoking on tear film and ocular surface. Korean J Ophthalmol 2005; 19: $18-22$.

42 Bron AJ, Tiffany JM, Gouveia SM, Yokoi N, Voon LW. Functional aspects of the tear film lipid layer. Exp Eye Res 2004; 78: 347-360.

43 Doane MG. Abnormalities of the structure of the superficial lipid layer on the in vivo dry-eye tear film. Adv Exp Med Biol 1994; 350: 489-493.

44 Kato Y, Yoshida A, Naito M, Kawai Y, Tsuji K, Kitamura M et al. Identification and quantification of $\mathrm{N}$ (epsilon)(Hexanoyl)lysine in human urine by liquid chromatography/tandem mass spectrometry. Free Radic Biol Med 2004; 37: 1864-1874.

45 Gipson IK, Hori Y, Argueso P. Character of ocular surface mucins and their alteration in dry eye disease. Ocul Surf 2004; 2: 131-148.

46 Tishler M, Yaron I, Geyer O, Shirazi I, Naftaliev E, Yaron M. Elevated tear interleukin-6 levels in patients with Sjogren syndrome. Ophthalmology 1998; 105: 2327-2329.

47 Virtanen T, Konttinen YT, Honkanen N, Harkonen M, Tervo T. Tear fluid plasmin activity of dry eye patients with 
Sjogren's syndrome. Acta Ophthalmol Scand 1997; 75: 137-141.

48 Afonso AA, Sobrin L, Monroy DC, Selzer M, Lokeshwar B, Pflugfelder SC. Tear fluid gelatinase B activity correlates with IL-1alpha concentration and fluorescein clearance in ocular rosacea. Invest Ophthalmol Vis Sci 1999; 40: 2506-2512.
49 Sobrin L, Liu Z, Monroy DC, Solomon A, Selzer MG, Lokeshwar BL et al. Regulation of MMP-9 activity in human tear fluid and corneal epithelial culture supernatant. Invest Ophthalmol Vis Sci 2000; 41: 1703-1709.

50 Smith VA, Rishmawi H, Hussein H, Easty DL. Tear film MMP accumulation and corneal disease. $\mathrm{Br} J$ Ophthalmol 2001; 85: 147-153. 